\title{
A Chapter of SugGestions, Fifty SugGestions, Marginalia E MARGINAL Notes: FractaIS DAS Teorias Estéticas de PoE? A Chapter of Suggestions, Fifty Suggestions, Marginalia and Marginal Notes: Would They be Fractals of Poe's Aesthetic Thoughts?
}

\author{
Renata Philippov*
}

Contista, poeta, crítico literário, revisor, editor de periódicos, Edgar Allan Poe debruçou-se sobre diversas formas literárias. Criador de contos de raciocínio e detetive, introdutor de ficção científica na literatura norte-americana, figura polêmica nos círculos literários da primeira metade do século XIX. Muito tem sido dito e publicado sobre a vida e obra do autor. Entretanto, na maioria das vezes, a crítica tem privilegiado a análise de seus contos (POE, 1975), considerados em geral, superiores aos poemas publicados por ele (à exceção, talvez de The Raven), poemas tidos como repetitivos, laudatórios e de qualidade duvidosa. Apenas alguns especialistas, entretanto, tem-se atido a outras obras do autor, tais como The Adventure of A.Gordon Pym, romance de viagem inacabado, ou ao drama The Polician, ambos pouco conhecidos do leitor comum. Menor importância ainda tem sido dada à análise de obras tais como Marginalia, Marginal Notes, A Chapter of Suggestions e Fifty Suggestions, coletâneas de pensamentos estéticos e 
críticas publicadas por Poe em diversos periódicos para os quais enviou textos e, por vezes, contribuiu enquanto revisor e editor e, que ainda aguardam uma tradução completa para o português.

Suas teorias estéticas, no entanto, tornaram-se alvo constante de análise por parte da crítica, desde sua morte em 1849. Em vida, vale salientar, a recepção de suas teorias e criações estéticas passou por altos e baixos: às vezes festejado e aclamado nos círculos literários para os quais contribuiu, recebendo alguns prêmios por contos e coletâneas de poemas, às vezes hostilizado pelos mesmos círculos, Poe alcançou fama, mas não um status definitivo, enquanto publicou. Postumamente, no começo, provavelmente contaminada por uma célebre biografia de cunho negativo lançada por Rufus Griswold, testamenteiro e rival literário de Poe, que se encarregou de denegrir a imagem do autor e fomentar um mito que até hoje persiste por parte do leitor comum, a análise da obra do autor norte-americano seguiu dois caminhos distintos: se por um lado, a crítica foi por muito tempo permeada por um cunho de "biografismo" relegando a sua estética e poética a segundo plano, por considerá-lo menor dentro do cânone literário norte-americano oitocentista, preferindo chamá-lo de alcoólatra, dependente de ópio, e desequilibrado, parte integrante de um mito que foi sendo criado em torno de sua reputação, por outro lado, a crítica pareceu, por muito tempo, não conseguir estar pronta para perceber o caráter inovador de sua estética e poética - como se Poe estivesse adiante de seu tempo em vários aspectos - preferindo preteri-lo a outros escritores de maior renome no cânone do período (Longfellow, Hawthorne, Melville).

Apenas na segunda metade do século XIX, Poe começou a receber uma análise mais apurada de sua obra, talvez devido à festejada recepção de autores franceses como Charles Baudelaire e Mallarmé, através dos quais o mundo passou a apreciar a obra de Poe, enquanto nos Estados Unidos o autor ainda era ironicamente visto como menor dentro do cânone. Fato é que o começo do século XX, com o advento do Modernismo e de estéticas iconoclastas e adeptas de fragmentação, trouxe uma grande ruptura na forma de ler a obra de Poe, com um princípio de consequente resgate de suas teorias e obras, vistas como modelos e precursoras da estética moderna. Entende-se o porquê de uma recepção mais positiva e aberta de teorias estéticas e poéticas que privilegiassem a fragmentação, a quebra de paradigmas, o novo, o inesperado, contribuições dos fragmentos das obras de Poe aqui discutidas. Em relação às teorias estéticas de Poe, vale mencionar a importância crucial de um efeito previamente escolhido pelo contista, a partir do qual a narrativa deveria ser pensada e para o qual deveria culminar, a busca da beleza centralizada por Poe na morte da mulher amada, a predominância do belo sobre o gosto (conceitos defendidos pelo autor em seu ensaio The Poetic 
Principle, 1850), a concisão textual como forma de captar a atenção do leitor, fazendo-o ler o texto de uma só vez e, assim, manter o efeito previamente desejado (como discutido no ensaio Philosophy of Composition, 1846, no qual Poe descreve o processo pelo qual teria elaborado seu mais famoso poema, The Raven), o respeito à forma poética e a tratados de versificação clássica (como analisa longa e profundamente em The Rationale of Verse, 1848), a valorização da sugestão em detrimento da explicitação na obra de arte e o predomínio do gênio criador sobre o talento artístico. Tais elementos teóricos, amplamente defendidos por Poe em seus ensaios e críticas literárias, como em Review of Twice-Told Tales, de Nathaniel Hawthorne (1842), parecem ter sido refletida e conscientemente empregados nos diversos contos e poemas publicados, tanto em vida, quanto postumamente. Assim, pode-se dizer que tais teorias estéticas e juízos de valor constituíram uma verdadeira obsessão, um projeto literário refletido e levado a cabo pelo autor e claramente percebido em todos os seus contos, poemas, ensaios e críticas.

Enquanto Poe, em sua teoria estética e produção literária, buscava a totalidade do texto ao preconizar insistentemente que tudo deveria culminar de forma una para um efeito pré-estabelecido, ao repetidamente afirmar que nada deveria ser incluído se não fosse para contribuir para a criação de tal totalidade e manutenção do efeito previamente escolhido, ao mesmo tempo, paradoxalmente, publicou fragmentos de textos em diversos periódicos, muitas vezes desordenados e sem continuidade, mas, às vezes, antes da publicação, procurava dar forma de texto aos fragmentos, ordenando-os. Segundo o próprio Poe, tais fragmentos por ele denominados Marginalia, seriam fruto de anotações dispersas às margens de livros aos quais havia dedicado um processo de leitura e análise durante o qual tecia comentários, anotava associações de ideias, elaborava críticas. Como diz no primeiro fragmento publicado no periódico Democratic Review, em novembro de 1844 , do hábito de fazer anotações às margens de livros ou em pedaços de papel depositados entre as páginas lidas, surgiu a intenção de compartilhar tais pensamentos e publicá-los:

[...] there might be something even in my scribblings which, for the mere sake of scribbling, would have interest for others ${ }^{1}$.

Ao decidir transferir tais fragmentos para uma publicação em periódicos, Poe nos diz o quão trabalhoso foi o processo, por demandar uma 
re-elaboração, uma junção de contextualização, sem as quais o leitor não poderia entender a que se referia:

The main difficulty respected the mode of transferring the notes from the volumes - the context from the text - without detriment to that exceedingly frail fabric of intelligibility in which the context was imbedded ${ }^{2}$.

No mesmo fragmento, Poe afirma ter decidido confiar na atenção e imaginação do leitor para uma compreensão do texto desprovido do contexto original, enquanto, caso necessário, remodelava a anotação para transmitir pelo menos um quê da concepção original, o que poderia significar transformar fragmentos em textos bem elaborados, como ocorreu diversas vezes. Assim, publicados entre novembro de 1844 e setembro de 1849 em diversos periódicos com tiragem mensal (The Opal, Democratic Review, Graham's Magazine, Godey's Lady's Book e Southern Literary Messenger), para os quais contribuiu por períodos de tempo variáveis enquanto revisor, articulista e editor, tais fragmentos estão hoje agrupados e publicados com os títulos de Marginalia, Marginal Notes, A Chapter of Suggestions e Fifty Suggestions, obras pouco estudadas pela crítica.

Dos quatro livros de fragmentos, o mais desenvolvido, sob o ponto de vista textual, é Marginalia, na medida em que vários dos fragmentos parecem mostrar um caráter ensaístico e, portanto, teriam sido desenvolvidos e imbuídos de maior contextualização por parte do autor. São um total de 246 fragmentos, não numerados e justapostos de forma aleatória, separados por pequenos traços, que vão desde sentenças soltas e carentes de contexto como "Jehovah is not Hebrew" 3 publicada em Democratic Review em dezembro de 1844 , até pequenos ensaios sobre poemas de outros escritores como Amélia Welby ${ }^{4}$ e retomadas de seus próprios poemas, como Lenore, e contos, como o poema Haunted Palace inserido no conto The Fall of the House of Usher, mencionados em fragmento publicado em Southern Literary Messenger em maio de $1849^{5}$. Assim, dado seu caráter de maior completude e fôlego ensaístico, Marginalia geralmente é tido como o único conjunto de fragmentos que Poe teria publicado.

$\mathrm{Na}$ realidade, os demais livros guardam maior concisão textual e menor volume de pensamentos e fragmentos. Fifty Suggestions, como o próprio nome antecipa, consiste de 50 pequenos fragmentos ou sugestóes

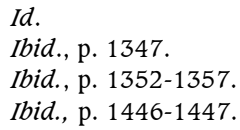


de pensamentos críticos dispostos de forma numerada e sequencial sobre diversos autores, teoria estética, conceitos de escritura e enunciação, publicados entre maio e junho de 1849 na Graham's Magazine. Aqui se percebe uma ordem pré-concebida pelo autor, o que não ocorre nos demais livros de fragmentos. Em A Chapter of Suggestions, publicado em The Opal em 1845 (não sabemos se de uma só vez ou não, devido à ausência de mês de publicação), temos a primeira impressão de que se trata de um capítulo de livro dado o título e a disposição do texto na página. No entanto, uma leitura mais aproximada permite perceber justaposição de 11 fragmentos desconexos escritos em sequência e com tênue separação entre eles marcada por um espaçamento maior entre tais fragmentos. Não há qualquer continuidade de tema nem coesão textual. Quanto a Marginal Notes, cujo subtítulo A Sequel to the Marginalia, aponta para um caráter de continuidade com relação à Marginalia, foi publicado entre agosto e setembro de 1845 em Godey's Lady's Book e consiste de um total de 39 fragmentos bastante breves, contendo unidade de sentido fechada em si mesmos e carregando o mesmo tipo de marcação tipográfica de Marginalia para separar cada fragmento. Entretanto, em um deles, Poe retoma a questão da brevidade como forma de garantir a leitura e compreensão, questão essa mais bem elaborada em seus ensaios de maior fôlego, como The Poetic Principle:

The increase, within a few years, of the magazine literature, is by no means to be regarded as indicating what some critics would suppose it to indicate - a downward tendency in American taste or in American letters. It is but a sign of the times, an indication of an era in which men are forced upon the curt, the condensed, the well-digested in place of the voluminous - in a word, upon journalism in lieu of dissertation. [...] I will not be sure that men at present think more profoundly than half a century ago, but beyond question they think with more rapidity, with more skill, with more tact, with more of method and less of excrescence of thought. [...] Hence the journalism of the age; hence, in especial, magazines ${ }^{6}$.

Assim, ao retomar nesse fragmento a questão da brevidade e analisar sua necessidade no gênero jornalístico enquanto uma imposição do mundo moderno, Poe simultaneamente justifica o uso de fragmentos em suas obras: fragmentos, em seu ponto de vista, condensariam o pensamento, seriam mais rápidos de serem digeridos, dada sua profundidade e 
brevidade. Portanto, apesar de aparentemente serem diferentes dos demais escritos do autor pelo caráter de fragmentação e incompletude que parecem estar em paradoxo com sua teoria estética em relação à totalidade de efeito, à completude de significação, à extrema coesão e coerência textuais que tanto preconizou em outros ensaios, poemas e contos, por outro lado, tais fragmentos parecem apontar para um uso inovador no cânone literário norte-americano de seu tempo, o uso que Poe fez dos fragmentos enquanto gênero textual embrionário não utilizado por outros escritores a ele contemporâneos.

Além disso, uma leitura mais atenta dos fragmentos contidos nos quatro livros permite perceber algumas constantes: a recorrência de críticas ferrenhas contra obras e autores contemporâneos ou anteriores a Poe, tanto norte-americanos como Longfellow quanto estrangeiros como Dickens, de defesas apaixonadas de obras e autores contemporâneos a ele (coincidentemente ou não, autores e obras cuja estética à dele se assemelhava - utilizar o outro para se justificar e autoafirmar eram características marcantes de sua veia crítica), denúncia de plágios cometidos contra suas obras, bem como contra a de outros autores, discussão sobre direito autoral internacional, batalha a favor ou contra opiniões críticas publicadas em periódicos, ou seja, recorrência de uma batalha literária e editorial.

Ademais, tem-se em tais fragmentos a presença forte e recorrente de características de sua própria teoria estética. De fato, assim como em seus ensaios bastante conhecidos (The Poetic Principle, Philosophy of Composition $e$ Rationale of Verse), percebe-se que o autor utiliza tais fragmentos constantemente para tecer considerações acerca da temática de grande parte de sua teoria estética, em questões tais como a busca da totalidade, a questão do efeito, o culto à beleza mostrada pela morte da mulher amada, a sugestão em detrimento da afirmação, a discussão sobre o gênio criador, a importância da versificação em poesia, o tamanho ideal do conto (nem muito curto, nem longo demais, para que o efeito almejado possa ser transmitido e não seja quebrado por interrupções de leitura), a importância da música, a correspondência sensorial, enfim, pode-se dizer que tais fragmentos podem ser lidos tanto como germes quanto consolidação de toda sua produção estético-poética. Como exemplo, pode-se citar um dos fragmentos de $A$ Chapter of Suggestions, publicado no periódico The Opal em 1845, em que trata da teoria da criação do efeito final da obra, antecedendo os ensaios mais conhecidos The Philosophy of Composition em um ano e The Poetic Principle em quatro anos (esse último postumamente publicado). Como diz Poe:

Pen should never touch paper, until at least a well-digested general purpose be established. In fiction, the dénouement- in all other composition the intended effect, should be definitely considered 
and arranged, before writing the first word; and no word should then be written which does not tend, or form a part of a sentence which tends, to the development of the dénouement, or to the strengthening of the effect ${ }^{7}$.

Se é nos ensaios que Poe realmente discute a teoria do efeito almejado pelo autor como forma de garantir a unidade de sentido e o impacto no leitor, essa e outras ideias aparecem de forma esparsa em fragmentos de textos publicados muitas vezes antes dos textos em que realmente discute sobre elas, ou seja, como germes ou consolidação de pensamentos e teorias estéticas discutidas com maior fôlego nos ensaios.

Mas por que fragmentos? O romantismo inglês e o romantismo alemão, antes mesmo de tal corrente chegar aos Estados Unidos, também recorreram ao uso estético de fragmentos como forma de mimetizar a perda de totalidade, um mundo em ruínas, a queda do homem diante de seu tempo. No entanto, de acordo com Beer (1996), o uso de fragmentos diferia dentre as diversas tendências românticas europeias. Enquanto os poetas da Lake School britânica (dentre os quais Coleridge e Wordsworth) privilegiavam a busca incessante da totalidade perdida e o uso de fragmentos para simbolizar uma totalidade já não mais existente, o romantismo alemão de F. Schlegel (192) e Schiller preferia o fragmento per se contendo unidade de sentido em si só, a ponto de criarem a "estética do fragmento" e publicarem tais fragmentos em revistas como Athenäum. De acordo com Beer, o fragmento para os românticos alemães constituía-se enquanto objetivo estético-filosófico, em vez de mero pretexto temático-metafórico como no romantismo inglês.

In thinking about the fragment as a literary form, it is helpful to turn to the work of Marjorie Levinson [...]. From her point of view the Romantic Fragment Poem can be viewed in its English manifestation from the end of the 18th century onward as a new mode, with common identifiable features. The reason for its emergence during the Romantic period, in her view, was the recognition by poets of their marginalized status in a mechanically dominated society, where they were expected to produce poems that were completed objects, to be consumed as such [...]. She is not suggesting, of course, that the fragment began its existence as a literary form in the $1790^{\prime} \mathrm{s}$. [...] It began with the ruins that presented their fragmentary forms everywhere in the landscape. The fragment, in this version, remained a part of that to which it had formerly belonged ${ }^{8}$.

Ibid., p. 1293.

LEVINSON, apud BEER, 1996. 
Beer discute a função e lugar do poeta no final do século XVIII e principalmente no século XIX, com a era de grandes mudanças políticas, sociais e econômicas (a Era Industrial, acima de tudo). O homem testemunha e sofre a exploração e fragmentação do trabalho, a alienação da consciência individual com relação a seu próprio meio social, a mecanização e a urbanização desenfreadas. De acordo com a leitura marxista de Beer, o artista enfrenta e reflete sobre tais mudanças profundas. De fato, ao enfrentar um mundo fragmentário, estranho e inquietante, o artista vê seu papel ser questionado. Para muitos, dentre os quais Poe, tal mundo não mais lhes permite a imaginação criadora. Assim, o fragmento gradualmente adquiriria um papel crucial de resistência e recusa com relação a tal processo de fragmentação e alienação do homem face à sociedade, em vez de tal fragmento meramente permanecer enquanto lócus de melancolia e sentido de perda inexorável de uma totalidade, como proposto pelos poetas da Lake School.

$O$ artista romântico, segundo Beer, portanto, procura novas formas de expressar e afirmar seu papel na sociedade e na arte. De fato, verbos tais como "evocar" e "sugerir" são frequentemente empregados por tais artistas (vide o título dos livros em forma de fragmentos escritos por Poe: A Chapter of Suggestions e Fifty Suggestions), com o intuito de expressar o obscuro, o inimaginável, o indefinido, sentimentos e conceitos provenientes de um mundo fragmentário. F. Schlegel (apud BEER, 1996) afirma que:

Many of the works of the ancients have become fragments; many of the works of the moderns are fragments in their arising 9 .

Portanto, ao se dedicar à escrita marginal ou fragmentária, Poe une-se à tradição dos românticos alemães, principalmente F. Schlegel e Schiller, no sentido de empregar o fragmento textual, ou seja, a queda textual, enquanto argumento e forma, enquanto manifestação de repúdio à alienação do artista no mundo moderno, à alienação do artista face ao cânone pré-estabelecido. No entanto, uma análise de tais fragmentos, justamente por demonstrar profunda ligação com o restante da obra estética de Poe, pode denotar que, para além do conceito de fragmento tal como defendido pelos românticos alemães, teria muito mais um caráter de fractal, conceito da matemática descrito pela primeira vez em 1975 e apropriado pela Teoria do Caos e pela Física Quântica, posteriores a Poe em mais de um século.

Segundo Mandelbrot (1986, p. 420-424), matemático que cunhou o termo, um fractal é um fragmento que tem a capacidade de condensar em 
seu interior todas as características do todo ao qual pertenceu, mesmo que tais características possam ser semelhantes, mas não totalmente iguais a esse todo. Se o cerne da teoria de Poe, bem como o de sua produção artística (contos, poemas, romance e drama inacabados), reside nas questões da busca de uma totalidade de efeito, na temática da morte da mulher amada como fonte de beleza suprema, na imaginação criadora do gênio, na importância da sugestão em detrimento do ato de dizer, na indefinição, na primazia da música e correspondência sinestésica, e se os fragmentos de $A$ Chapter of Suggestions, Fifty Suggestions, Marginalia e Marginal Notes retomam com bastante recorrência tal cerne, pode-se dizer que tais fragmentos seriam fractais da teoria estético-poética de Edgar Allan Poe, embora, às vezes, tenham deixado de lado tais teorias para travar uma batalha contra ou a favor de outros autores e obras, usando de ironia fina, ou por vezes, crítica direta e ferrenha ou elogios beirando a bajulação, como em "Mr. Hawthorne is one of the very few American story-tellers whom the critic can commend with the hand upon the heart" ${ }^{10}$. Afinal, se o fractal é, segundo Mandelbrot, algo semelhante ao todo ao qual pertenceu, pode-se dizer que os fragmentos de Poe seriam fractais em si, na medida em que tendem a se remeter quase que incessantemente ao corpus de sua teoria estética, discorrendo sobre alguns dos temas mais caros ao escritor norte-americano, tais como o gênio criador, a brevidade textual, a versificação clássica, a beleza, a sugestão, a sinestesia, o indefinido e a música.

Por outro lado, dado o caráter de ausência de contextualização em alguns fragmentos, de hermetismo quase indecifrável em alguns momentos, bem como o combate e diálogo acirrado contra ou a favor de alguns de seus contemporâneos, alguns de tais excertos paradoxalmente parecem se destacar ao divergir muitas vezes do cerne da obra de Poe, e pairar de forma bastante desconexa ao lado de outros fragmentos diretamente ligados a seus escritos. Assim, nem todos os fragmentos parecem ligados ao âmago da obra do autor, talvez por ausência de maior detalhamento e contextualização, talvez pela necessidade de aderir a querelas literárias.

Afinal, se fractais são semelhantes ao todo ao qual pertencem, mas não necessariamente iguais a ele, pode-se ler os fragmentos publicados em A Chapter of Suggestions, Fifty Suggestions, Marginalia e Marginal Notes como fractais, algo inédito no cânone literário norte-americano da primeira metade do século XIX, cronotopo de Poe, para remeter ao conceito bakhtiniano que alia tempo e espaço ao descrever uma obra literária. De fato, nenhum outro escritor norte-americano contemporâneo a Poe dedicou-se a publicar fragmentos de texto, preferindo apenas recorrer a fragmentos enquanto

$10 \quad$ POE, 1984, p. 1343. 
temática para a aniquilação do homem diante de um mundo em ruínas, em decadência física e moral (casas se esfacelam, a moral entra em decadência, o mundo rui). Assim, Poe parece ter avançado bastante para além de seu tempo e cânone (ao retomar a estética do fragmento do romantismo alemão e introduzir o fragmento enquanto gênero textual), o que, talvez, possa explicar a incompreensão sofrida por sua obra e teoria estética até o final do século XIX, provavelmente ocasionada por uma crítica não preparada para ver em sua obra o caráter de fragmentação e fractalização presente em A Chapter of Suggestions, Fifty Suggestions, Marginalia e Marginal Notes. Seria preciso aguardar até o começo do século XX, pela estética do modernismo, para que se pudesse começar a entender o caráter inovador da obra de Edgar Allan Poe, dada a primazia da fragmentação dentre as estéticas do período. Entretanto, a crítica da obra de Poe parece ainda engatinhar no que se refere aos fragmentos, ou melhor, fractais presentes em $A$ Chapter of Suggestions, Fifty Suggestions, Marginalia e Marginal Notes, por muito tempo relegados a papel secundário ou terciário dentre a produção do autor norte-americano, talvez por mera incompreensão de sua relevância enquanto inovação e retomada de toda a teoria estética do autor. De fato, poucos são os estudos dedicados a tais coletâneas, poucas são as análises de tais obras, pouco tem sido dito pela crítica até o presente momento.

Portanto, se por um lado uma compreensão mais acertada e profunda dos fragmentos presentes em tais livros dependeu de inovações estéticas que surgiram de forma impactante no começo do século XX e das contribuições de Mandelbrot, da Teoria do Caos e da Física Quântica acerca dos fractais para se perceber o diálogo entre tais fragmentos e o restante da obra de Poe, por outro, talvez sem Poe, tais inovações não tivessem sido introduzidas nem sequer pensadas: de incompreendido, relegado a segundo plano, desprezado por boa parte do cânone de seu tempo, Poe poderia passar a ser visto como precursor de toda uma estética moderna e pós-moderna, o que explicaria a recepção festejada na França da segunda metade do século XIX, reconhecido berço de inovações estéticas abraçadas e radicalizadas pela estética moderna e pós-moderna. Assim sendo, de escritor menor dentro de seu cânone, Poe passaria a alçar um status de precursor de uma grande revolução em termos de estética e poética, status, portanto, de contemporaneidade com relação à pós-modernidade.

Deste modo, além de contista, editor, poeta, introdutor de contos de raciocínio e detetive, como Poe é conhecido, talvez deva ser acrescentado a tal lista o título de introdutor do fragmento enquanto gênero textual, bem como do uso estético que dele fez Poe. Portanto, este artigo pretendeu apontar para o fato de A Chapter of Suggestions, Fifty Suggestions, Marginalia e Marginal Notes poderem ser lidos dentro do conjunto de obras do autor mais 
conhecidas do público e mais estudadas pela crítica (os contos, o poema The Raven e os ensaios The Poetic Principle e Philosophy of Composition, principalmente) enquanto fractais de toda a teoria estética e poética de Edgar Allan Poe, posto que parece efetivamente remeter ao pensamento estético do autor e dialogar com sua poética de forma bastante consciente e incisiva.

\title{
RESUMO
}

A crítica sobre a obra de Edgar Allan Poe parece ter relegado $A$ Chapter of Suggestions, Fifty Suggestions, Marginalia e Marginal Notes a uma posição de menor interesse e importância dentro do corpus de produção artística e crítica do autor. Entretanto, tais obras podem ser consideradas verdadeiros fractais, sob as perspectivas da Física Quântica e Teoria do Caos, por recorrentemente abarcar o cerne das teorias críticas e estéticas de Poe de forma bastante fragmentada ou fractalizada. Esta comunicação, portanto, almeja fazer uma leitura de tais obras para analisar o uso de fragmentação textual e temática por parte do autor, fenômeno esse igualmente presente em seus contos e poemas, mas talvez menos contemplado pela crítica, o que possivelmente marca sua contemporaneidade de produção e pensamento estético e, ao mesmo tempo, distancia-o do cânone literário do século XIX norte-americano.

Palavras-chave: Poe; fractais; Teoria estética.

\begin{abstract}
Criticism on Edgar Allan Poe's works seems to have relegated A Chapter of Suggestions, Fifty Suggestions, Marginalia and Marginal Notes to a position of minor interest and importance within the author's artistic and critical production. However, those works may be considered true fractals, under the perspective of Quantum Physics and Chaos Theory, for they recurrently embrace the core of Poe's critical and aesthetic theories in quite a fragmentary or fractalized way. This paper, therefore, aims at reading such works to analyze Poe's use of textual and thematic fragmentation, a phenomenon equally present in his tales and poems, but perhaps less studied by critics, a fact which probably marks the contemporaneity of his production and aesthetic thought, and, at the same time, it distances him from the 19th century North-American literary canon.
\end{abstract}

Keywords: Poe; fractals; Aesthetic theory. 
PHilippov, R. A Chapter of Suggestions, Fifty Suggestions, Marginalia E...

\section{REFERÊNCIAS}

BEER, John. (Ed.). Questioning Romanticism. Baltimore: Johns Hopkins University, 1996.

LEVINSON, M. The Romantic Fragment Poem: a critique of a form. 1996.

MANDELBROT, Benoît. Comment j'ai decouvert les fractales. La Recherche, 1986, p. 420-424.

POE, Edgar Allan. Complete Tales and Poems. New York: Vintage Books, 1975.

. Essays and Reviews. New York: Library of America, 1984.

SCHLEGEL, Friedrich. $O$ dialeto dos fragmentos. Tradução de: SUZUKI, Márcio. São Paulo: Iluminuras, 1992.

Submetido em: 30/10/2009

Aceito em: 11/01/2010 